\title{
The Comparison of Effects of Applications of Compound 48/80 and Mast Cell Mediator Suspension on Inflammation in Rats: A Methodological Study for Acute Inflammatory Pain
}

\author{
Erkan Kilinc $^{1}$ (D), Yasar Dagistan² (D) Ayhan Cetinkaya $^{1}$ (D) Fatma Tore $^{3}$ (D) \\ ${ }^{1}$ Department of Physiology, Faculty of Medicine, Abant Izzet Baysal University, Bolu, Turkey \\ ${ }^{2}$ Department of Neurosurgery, Faculty of Medicine, Abant Izzet Baysal University, Bolu, Turkey \\ ${ }^{3}$ Department of Physiology, Faculty of Medicine, Biruni University, Istanbul, Turkey \\ Correspondence Author: Erkan Kilinc \\ E-mail: e_kilinc_27@hotmail.com \\ Received: $03.01 .2018 \quad$ Accepted: 07.02 .2018
}

\begin{abstract}
Objective: Inflammation underlies the pathological basis of most diseases. Substance-P is a key mediator that participates in various inflammatory processes and painful conditions. Mast cells (MCs) have a key role in inflammatory processes via mediators released from their granules. The experimental models for the investigation of pathogenesis and treatment of inflammatory diseases represent merely certain characteristics of inflammatory cases, therefore, more comprehensive models are required. We aimed to compare effects of administrations of the compound-48/80 and mast cell mediator suspension (MCMS) obtained from peritoneal MCs on the inflammation in rats.

Methods: Rats were divided into five groups $(\mathrm{n}=6)$ : Intraperitoneally, Control group received $0.2 \mathrm{ml}$ saline; C- $48 / 80$ group received $2 \mathrm{mg} / \mathrm{kg}$ compound-48/80; MCMS group received $0.2 \mathrm{ml} \mathrm{MCMS;} \mathrm{Cr}+\mathrm{C}-48 / 80$ group received $10 \mathrm{mg} / \mathrm{kg}$ cromolyn plus compound-48/80; $\mathrm{Cr}+\mathrm{MCMS}$ group received cromolyn plus MCMS. Potent inflammatory markers, plasma substance-P levels, and number and degranulation of dural MCs were measured. Data were analyzed using one-way ANOVA followed by Dunnett's post hoc test.

Results: Compound-48/80 increased plasma substance-P levels $(p<0.05)$ and dural MC-degranulation $(p<0.001)$. Likewise, MCMS increased substance-P levels and dural MC-degranulation $(p<0.001)$ as well as number of dural MCs $(p<0.01)$. MC stabilizer cromolyn inhibited increases in the parameters induced by compound- $48 / 80$ and MCMS $(p<0.01$ and $p<0.05$, respectively).

Conclusion: MCMS administration had greater impact to increase the plasma substance-P levels and number and degranulation of dural MCs than that of the compound-48/80 administration. The results demonstrate the potent inflammatory effect of MCMS treatment over the compund- $48 / 80$ administration. Administration of MCMS could be a useful tool to study inflammatory conditions.

Keywords: Inflammatory pain, mast cell degranulation, substance-P, compound-48/80.
\end{abstract}

\section{INTRODUCTION}

Inflammation is a complex biological response of tissues to endogen or exogen detrimental stimuli. Acute inflammation is induced by various stimuli including chemical mediators generated by damaged host cells, infections, chemical agents, tissue injuries, and immune reactions. Inflammation is characterized by pain, swelling, and leukocyte infiltration in the site of injury (1). Mast cells (MCs) are tissue resident inflammatory cells participating in immune responses during inflammatory reactions (2). Normally activation of MCs is useful to establish homeostasis of body systems, but their over activation can chronically induce inflammatory responses such as in the case of asthma and arthritis (3). MCs participate in the inflammatory processes by releasing various pronociceptive, vasoactive and pro-inflammatory mediators from their granules through a process called degranulation (4). MCderived mediators such as serotonin, prostaglandin, histamine, tryptase, tumor necrosis factor-alpha (TNF- $\alpha$ ), and interleukin (IL)- $1 \beta$ are able to trigger and enhance inflammatory reactions (5). Increments in the number and degranulation of MCs in their resident environment contribute to hyperalgesia in various rodent models of pain $(6,7)$. It was previously reported that chronic inflammatory processes following pathological stimuli can be restrained by application of mast cell stabilizing agents such as ketotifen and cromolyn $(8,9)$.

Substance $P(S P)$ is a neuropeptide consisting of 11 amino acids and is produced by neurons and cells of the immune system such as MCs, macrophages, and dendritic cells. It exerts its effects by binding to the neurokinin-1 receptor (NK-1R) (10). SP is a crucial mediator of inflammation, and plays a key role in the generation and maintenance of inflammation. It is involved in the pathophysiology of various inflamatory diseases such as rheumatoid arthritis and joint inflammation $(11,12)$. SP participates in the inflammatory processes by inducing the release of proinflammatory cytokines such as IL-1, IL-2 and TNF- $\alpha$ from various cells (13). Inhibition of substance $P$ activity by using NK-1 receptor antagonists or via gene deletion produces potent anti-inflammatory analgesic effects (14) and reduces edema formation in humans (15). Increased number and enhanced degranulation of MCs, and increased 
SP levels accompanying hyperalgesia have been involved in various pathologies associated with pain (7).

Animal models of inflammatory pain are important tools to investigate pain mechanisms and analgesic effects of potential drugs for the treatment of inflammatory diseases. Various inflammatory substances including inflammatory cytokines, formalin, lipopolysaccharide and Freund's adjuvant have been used to construct animal models of inflammatory pain via application of these substances to cutaneous tissues, joints and muscles (16). Yet, none of these models mimic all the characteristics of inflammatory pains, however, they represent certain points of inflammatory pain conditions. Herein, we have compared effects of intraperitoneal administrations of the basic secretagogue agent compound $48 / 80$ which is used to produce hyperalgesia and inflammation associated with the degranulation of mast cells as well as mast cell mediator suspension obtained from peritoneal MCs on the inflammation in rats.

\section{METHODS}

\subsection{Experimental Animals}

Thirty male Wistar rats weighing 170-200 g were used in present study. The rats received a standard pellet diet and water ad libitum and were housed in their cages with a 12 hour light/dark cycle at $22 \pm 2{ }^{\circ} \mathrm{C}$. All experimental applications were approved by Animal Experiments Local Ethics Committee of Abant Izzet Baysal University (licence number 2017/23).

\subsection{Reagents}

Compound 48/80, cromolyn sodium salt, toluidine blue, phosphate-buffered saline (PBS) and paraformaldehyde (PAF) were purchased from Sigma-Aldrich, (Schnelldorf, Germany). Substance-P ELISA kit was purchased from ELABscience (Wuhan, P.R. China ).

\subsection{Experimental groups and treatments}

Thirty rats were randomly divided into five groups with six rats in each group. Intraperitoneal administration were performed as follows; rats in control group $(n=6)$ were administered with $0.2 \mathrm{ml}$ normal saline; rats in $\mathrm{C}-48 / 80$ group $(\mathrm{n}=6)$ were administered with mast cell degranulating agent $2 \mathrm{mg} / \mathrm{kg}$ compound 48/80 (17); rats in mast cell mediator suspension (MCMS) group $(n=6)$ were administered with $0.2 \mathrm{ml}$ autologous mast cell mediator suspension $\left(1.5 \times 10^{5} / \mathrm{ml}\right.$ cells); 30 min prior to the administration of compund $48 / 80$, rats in Cromolyn+C-48/80 group $(n=6)$ were treated with mast cell stabilizer agent with an amount of $10 \mathrm{mg} / \mathrm{kg}$ cromolyn sodium (8); 30 min prior to the administration of $0.2 \mathrm{ml}$ autologous mast cell mediator suspension, rats in Cromolyn+MCMS group $(\mathrm{n}=6)$ were treated with $10 \mathrm{mg} / \mathrm{kg}$ cromolyn sodium.

\subsection{Isolation of peritoneal mast cells from rats}

Peritoneal mast cells were obtained from rats using peritoneal saline washing method as previously described (18). Rats were anesthetized with ketamine $(90 \mathrm{mg} / \mathrm{kg}$, i.p.). Peritoneal lavage was carried out by injecting $10 \mathrm{ml}$ normal saline containing heparin $(5 \mathrm{U} / \mathrm{ml})$ into peritoneal cavity. Abdominal massage was gently applied to the rats for $4 \mathrm{~min}$. Then, $6 \mathrm{ml}$ of peritoneal mast cell rich fluid was collected with a $10 \mathrm{ml}$ syringe from the peritoneal cavity. The fluid was then centrifuged at $32 \mathrm{~g}$ for 2 min at room temperature. Precipitated peritoneal mast cells were mingled in $1 \mathrm{ml} \mathrm{PBS}$ and counted using a thoma chamber. To obtain mast cell mediator suspension, peritoneal mast cells in PBS were treated with compound-48/80 (10 $\mathrm{gg} / \mathrm{ml})$ for $15 \mathrm{~min}$ at $37^{\circ} \mathrm{C}$ (17). Isolation of peritoneal mast cells were carried out to all rats to standardize experimental groups, but only rats in the MCMS and Cromolyn+MCMS groups were exposed to injections of $0.2 \mathrm{ml}$ autologous mast cell mediator suspension $\left(1.5 \times 10^{5} /\right.$ $\mathrm{ml}$ cells). Intact and compound 48/80-induced degranulated peritoneal mast cells are shown in Figures $1 \mathrm{~A}$ and $1 \mathrm{~B}$.

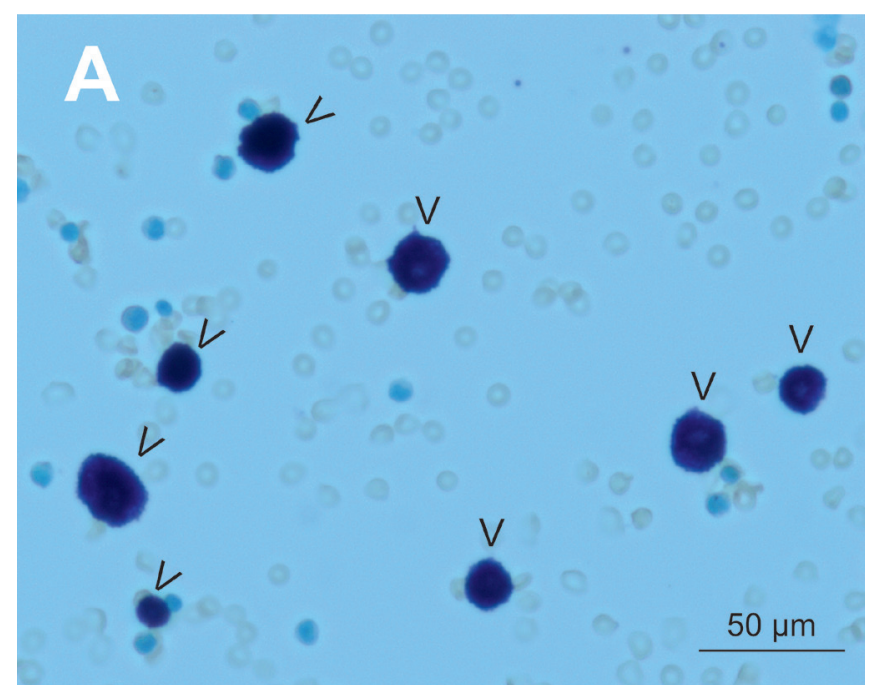

Figure $1 A$. Intact peritoneal mast cells before compound $48 / 80$ treatment in vitro. X40 magnification. Open arrowheads show intact mast cells (staining, toluidine blue).

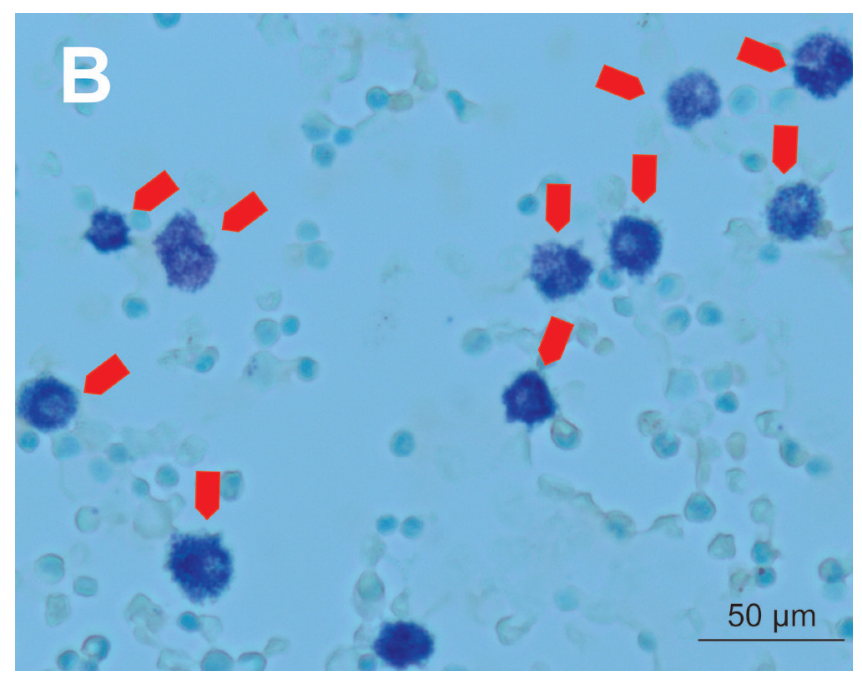

Figure 1B. Degranulated peritoneal mast cells after compound 48/80 treatment in vitro. X40 magnification. Red solid arrowheads show degranulated mast cells (staining, toluidine blue). 


\subsection{Blood sample collection from animals}

Two and a half hours after administration of drugs or autologous mast cell mediator suspension all rats were anesthetized with ketamine $(90 \mathrm{mg} / \mathrm{kg}$, i.p.). Blood was collected intracardially and coagulated at room temperature for $30 \mathrm{~min}$. The blood samples were centrifuged at $3000 \mathrm{rpm}$, at $4{ }^{\circ} \mathrm{C}$ for $15 \mathrm{~min}$. The supernatants were stored at $-20{ }^{\circ} \mathrm{C}$ until assayed for substance-P immunoreactivity.

\subsection{Dura mater preparations and toluidine blue staining for dural mast cells}

After blood sample collection, all rats were instantly perfused intracardially with $100 \mathrm{ml}$ phosphate-buffered saline (PBS; 0.1 $\mathrm{M}, \mathrm{pH}$ 7.4) and PBS followed by $200 \mathrm{ml}$ 4\% paraformaldehyde. After perfusion process, whole-mount preparations of cranial dura mater were prepared on the glass slides as described previously (19). Briefly, the head was separated from the body, the skulls were opened carefully, and the dura maters were removed. The dura maters were postfixed in $4 \%$ paraformaldehyde solution overnight. Then, the dura maters were stained with toluidine blue staining $(\mathrm{pH}: 2.5)$ to observe mast cells in dura mater. Mast cells were counted in five objective areas including the main branches of the middle meningeal artery in both sides of dura mater, and categorized with regards to granulation or degranulation under a light microscope (Olympus CX21) by a blinded observer. The granulation term refers to the intact mast cells, on the contrary degranulation term expresses mast cells at the activated state that release various mediators such as histamine, prostaglandin, IL-1 $\beta$ from their cytoplasmic granules to outside the cell. The percent of degranulated mast cells in each dura mater was calculated as follows: [(number of degranulated mast cells)/ (number of total mast cells)] X 100\%. Number of total mast cells and the percent of degranulated mast cells were calculated, and their microscopic images were taken with a camera (Nikon DS-Fi1, Nikon, Japan) which was attached to the microscope (Nikon Eclipse 80i, Nikon, Japan).

\subsection{Measurement of substance-P levels in plasma}

Substance-P content of plasma was measured using ELISA method with detection kits. The Substance-P detection limit is approximately $46.88 \mathrm{pg} / \mathrm{ml}$. The protocol was carried out in reference to the manufacturer's instructions and in duplicates. Briefly, $50 \mu \mathrm{L}$ of substance-P standard or plasma samples were added to each well. Immediately after, $50 \mu \mathrm{L}$ of biotinylated detection $A b$ was added to each well and the plates were incubated at $37{ }^{\circ} \mathrm{C}$ for $45 \mathrm{~min}$. Followed by removal of liquid from each well $100 \mu \mathrm{L}$ of HRP conjugate were added and the 96-well plates were incubated for $30 \mathrm{~min}$ at $37^{\circ} \mathrm{C}$. After the incubation, the wells were rinsed for 5 times with the wash buffer. Then $90 \mu \mathrm{L}$ of substrate reagent was added to each well, finally, the plate was incubated for $15 \mathrm{~min}$ at $37^{\circ} \mathrm{C}$. After the incubation, $50 \mu \mathrm{L}$ of stop solution was added to each well quickly. Then, optical density was measured at $450 \mathrm{~nm}$ using a microplate reader (Epoch BioTek Instruments, Inc. Highland Park, Winooski, VT, USA). Optical density curve was constituted by using standards with defined substance-P concentrations.

\subsection{Statistical analysis}

The data were stated as mean \pm standard error of mean. Statistical analysis was performed using SPSS for Windows (version 17.0, SPSS Inc., Chicago, IL, USA). Statistical differences were determined using one-way analysis of variance test (ANOVA) followed by Dunnett's post hoc test. $p<0.05$ was considered as statistically significant.

\section{RESULTS}

To activate mast cell degranulation, we used basic secretagogue agent compound $48 / 80$, which leads to systemic mast cell degranulation through the body when administered intraperitoneally. Therefore intraperitoneal administration of compound 48/80 (2 mg/kg) induced massive degranulation of mast cells in the dura mater compared to controls (from $6.7 \pm 0.4 \%$ to $45.6 \pm 3.5 \%, p=0.0002$, Figs. $2 A, 2 B$ and $3 A$ ).

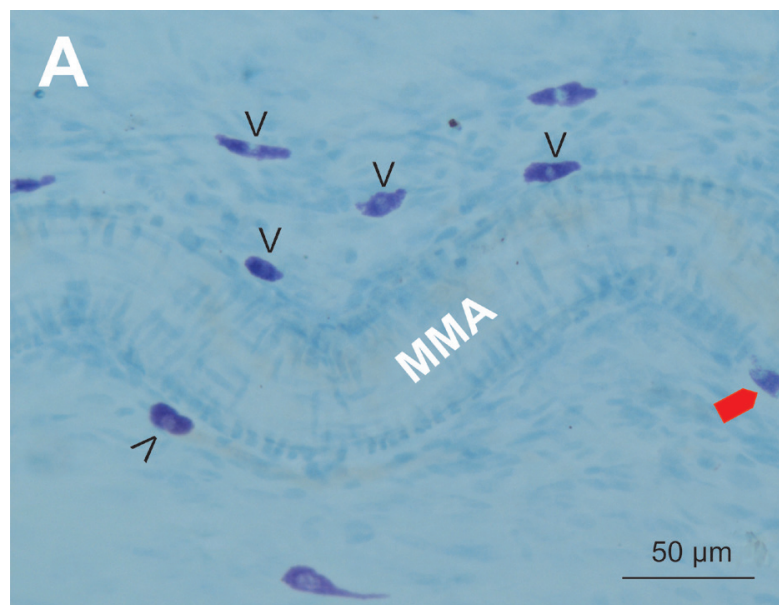

Figure 2A. Normally intact mast cells in the dura mater in control group. X20 magnification. While open arrowheads show intact mast cells, red solid arrowheads show degranulated mast cells (staining, toluidine blue). MMA: middle meningeal artery.

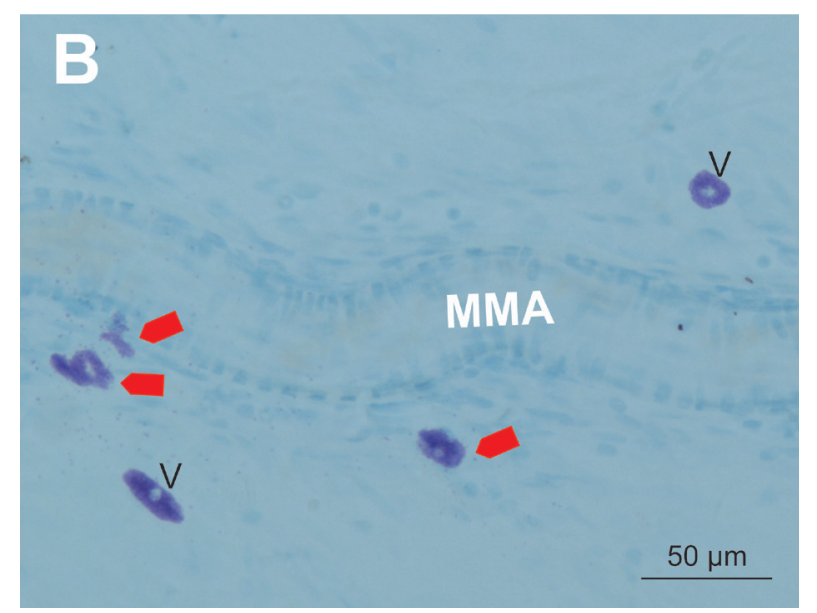

Figure 2B. Compound 48/80-induced degranulation of mast cells in the dura mater in compound 48/80 treatment group. X20 magnification. While open arrowheads show intact mast cells, red solid arrowheads show degranulated mast cells (staining, toluidine blue). MMA: middle meningeal artery. 


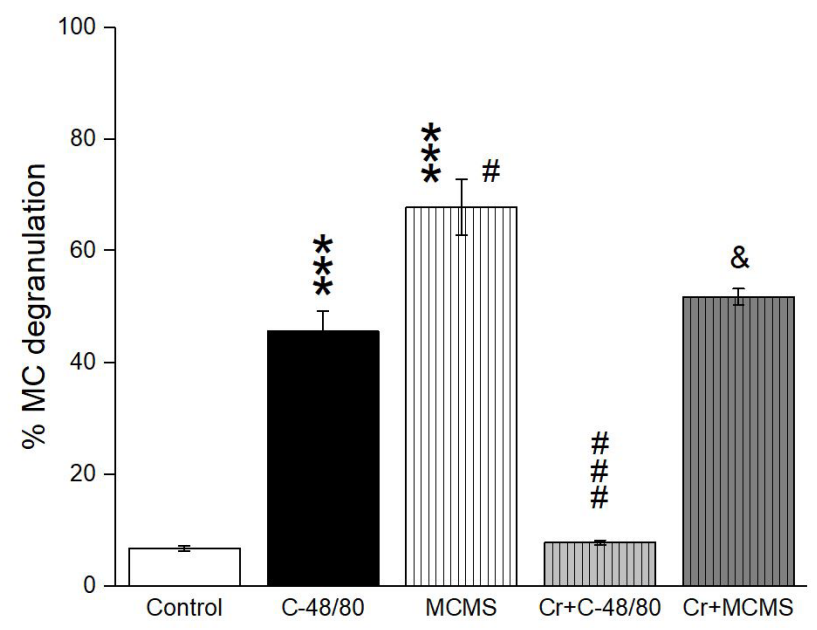

Figure 3A. While compound $48 / 80$ and mast cell mediator suspension increased the percent of degranulated mast cells, these increments were inhibited by cromolyn, respectively. Mast cell mediator suspension further increased dural mast cell degranulation to compound $48 / 80$. (***P<0.001, * versus control group; $\# P<0.05$ and \#\#\#P<0.001, \# versus compound 48/80 group; $\& P<0.05, \&$ versus mast cell mediator suspension group). $M C$ : mast cell, C-48/80: compound 48/80, MCMS: mast cell mediator suspension, Cr: cromolyn.

Moreover, intraperitoneal administration of compound 48/80 also increased plasma substance-P levels compared to controls (from $121.6 \pm 5.1 \mathrm{pg} / \mathrm{ml}$ to $154.5 \pm 4.3 \mathrm{pg} / \mathrm{ml}, \mathrm{p}=0.01$, Fig. 4), but it did not change total mast cell numbers in the dura mater compared to controls (from $358 \pm 20$ to $360 \pm 10, p=0.87$, Fig. 3B).

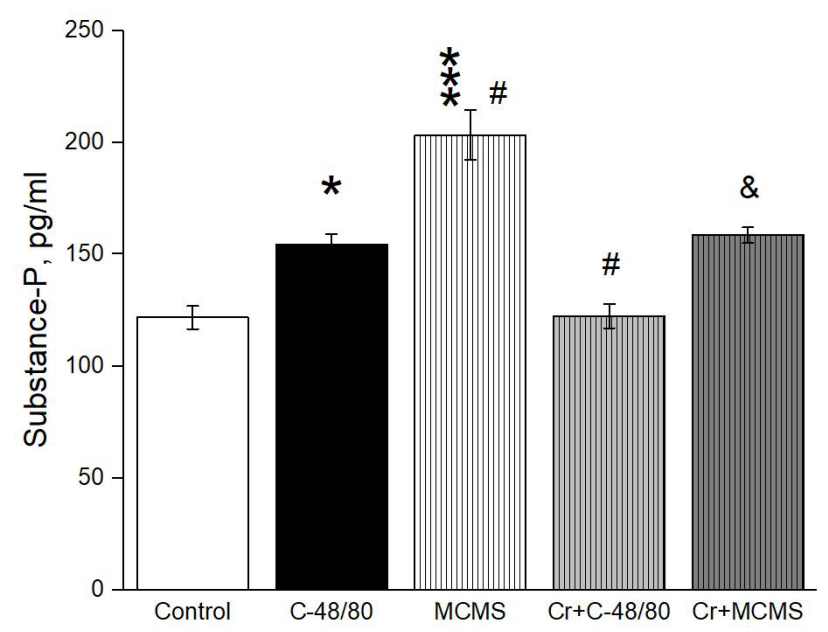

Figure 4. While compound $48 / 80$ and mast cell mediator suspension increased the plasma substance-P levels, these increments were inhibited by cromolyn, respectively. Mast cell mediator suspension further increased the plasma substance- $P$ levels to compound $48 / 80$. ( ${ }^{*} P<0.05$ and ${ }^{*} * P<0.001$, * versus control group; \#P<0.05, \# versus compound $48 / 80$ group; $\& P<0.05, \&$ versus mast cell mediator suspension group). $C-48 / 80$ :

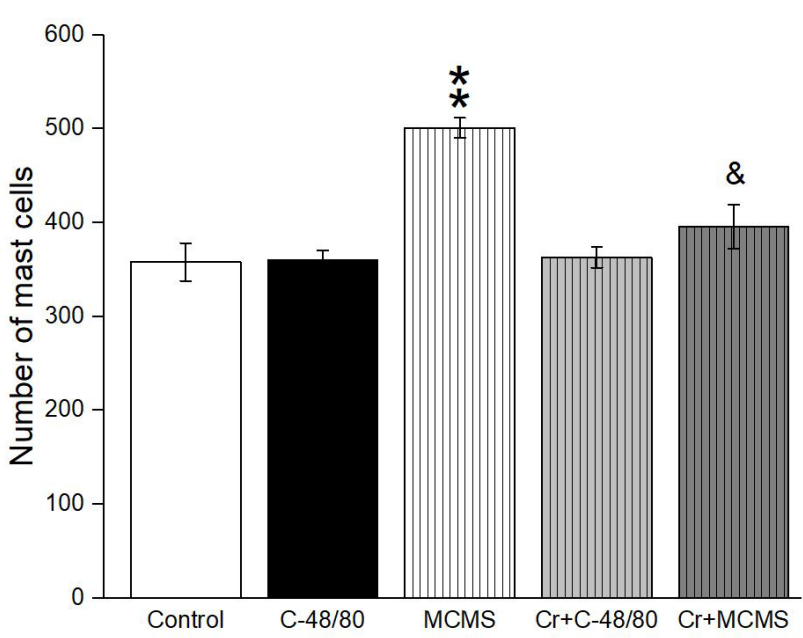

Figure 3B. While mast cell mediator suspension increased the number of mast cells in the dura mater, compound $48 / 80$ did not change it. Cromolyn decreased the increments in the number of mast cells in the dura mater induced by mast cell mediator suspension. ${ }^{* *} P<0.01$, * versus control group; \&P<0.05, \& versus mast cell mediator suspension group).

To verify these effects of compound $48 / 80$, we tested whether cromolyn sodium, a mast cell stabilizer, would prevent the actions induced by compound $48 / 80$. When cromolyn was administered with compound $48 / 80$ together, it blocked the effects of compound 48/80. Therefore cromolyn (10 mg/kg) prevented degranulation of mast cells in dura mater $(45.6 \pm 3.5 \%$ in $\mathrm{C}-48 / 80$ group versus $7.7 \pm 0.4 \%$ in Cromolyn+C-48/80 group, $\mathrm{p}=0.0003$, Figs. $2 \mathrm{C}$ and $3 \mathrm{~A}$ ), and also it inhibited the increases in plasma substance-P levels induced by compound $48 / 80$ $(154.5 \pm 4.3 \mathrm{pg} / \mathrm{ml}$ in C-48/80 group versus $122.3 \pm 5.4 \mathrm{pg} / \mathrm{ml}$ in Cromolyn+C-48/80 group, $p=0.007$, Fig. 4).

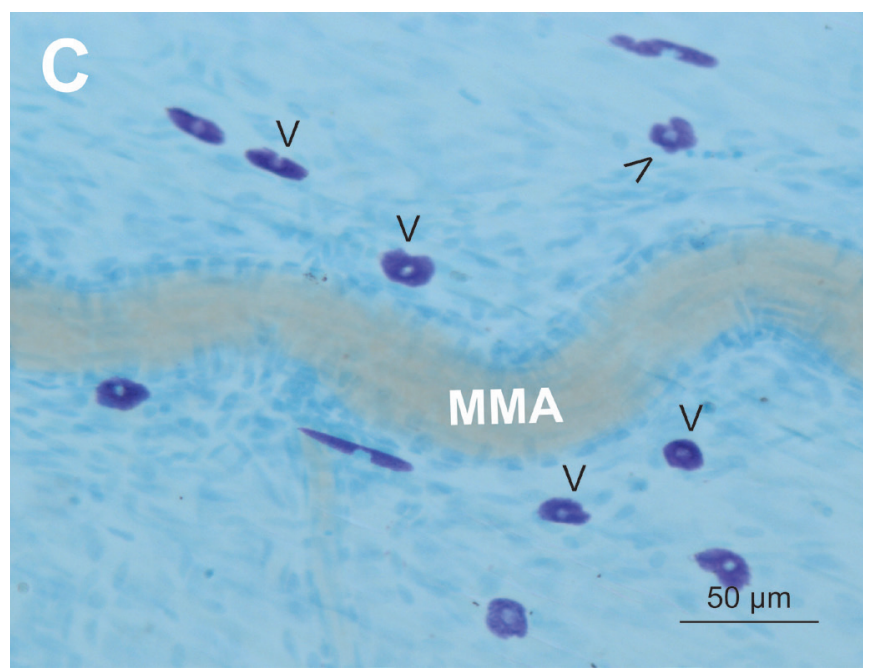

Figure 2C. Inhibition of mast cell degranulation in the dura mater by cromolyn in cromolyn plus compound $48 / 80$ group. $X 20$ magnification. Open arrowheads show intact mast cells (staining, toluidine blue). MMA: middle meningeal artery. 
On the other hand, to compare effects of compound $48 / 80$ and autologous mast cell mediator suspension, we first isolated peritoneal mast cells (Fig. 1A) and degranulated them by treating compound $48 / 80(10 \mu \mathrm{g} / \mathrm{ml})$ in vitro (Fig. $1 \mathrm{~B})$. Then, autologous mast cell mediator suspension was administered to the rats, immediately. Autologous mast cell mediator suspension administration significantly increased both the percent of degranulated mast cells (from $6.7 \pm 0.4 \%$ to $67.7 \pm 4.9 \%, p=0.0001$, Figs. $2 \mathrm{D}$ and Fig. $3 \mathrm{~A}$ ) and total mast cell numbers (from $358 \pm 20$ to $501 \pm 10, p=0.002$, Fig. $3 B$ ) in the dura mater. It also increased plasma substance-P levels (from $121.6 \pm 5.1 \mathrm{pg} / \mathrm{ml}$ to $203.1 \pm 11.1 \mathrm{pg} / \mathrm{ml}, \mathrm{p}=0.0001$, Fig. 4) compared to control. Interestingly, the triggering effect of mast cell mediator suspension administration on the degranulation of mast cells in the dura mater $(45.6 \pm 3.5 \%$ in $\mathrm{C}-48 / 80$ group versus $67.7 \pm 4.9 \%$ in $\mathrm{MCMS}$ group, $\mathrm{p}=0.047$, Figs. 2B, 2D and $3 \mathrm{~A}$ ) and plasma substance-P levels $(154.5 \pm 4.3 \mathrm{pg} / \mathrm{ml}$ in $\mathrm{C}-48 / 80$ group versus $203.1 \pm 11.1 \mathrm{pg} /$ $\mathrm{ml}$ in MCMS group, $\mathrm{p}=0.015$, Fig. 4) was stronger than that of the compound $48 / 80$. To clarify possible mechanism of these strong actions of mast cell mediator suspension, we tested whether cromolyn would inhibit the effects induced by mast cell mediator suspension. The results showed that cromolyn significantly attenuated both the percent of degranulated mast cells $(67.7 \pm 4.9 \%$ in MCMS group versus $51.7 \pm 1.4 \%$ in Cromolyn+MCMS group, $p=0.045$, Figs. 2D, $2 \mathrm{E}$, and $3 \mathrm{~A}$ ) and total mast cell numbers (501 \pm 10 in MCMS group versus $396 \pm 23$ in Cromolyn+MCMS group, $p=0.012$, Fig. $3 \mathrm{~B}$ ) in the dura mater. It also reduced autologous mast cell mediator suspension administration induced plasma substance-P levels $(203.1 \pm 11.1 \mathrm{pg} / \mathrm{ml}$ in MCMS group versus $158.5 \pm 3.5 \mathrm{pg} / \mathrm{ml}$ in Cromolyn+DM group, $\mathrm{p}=0.006$, Fig. 4).

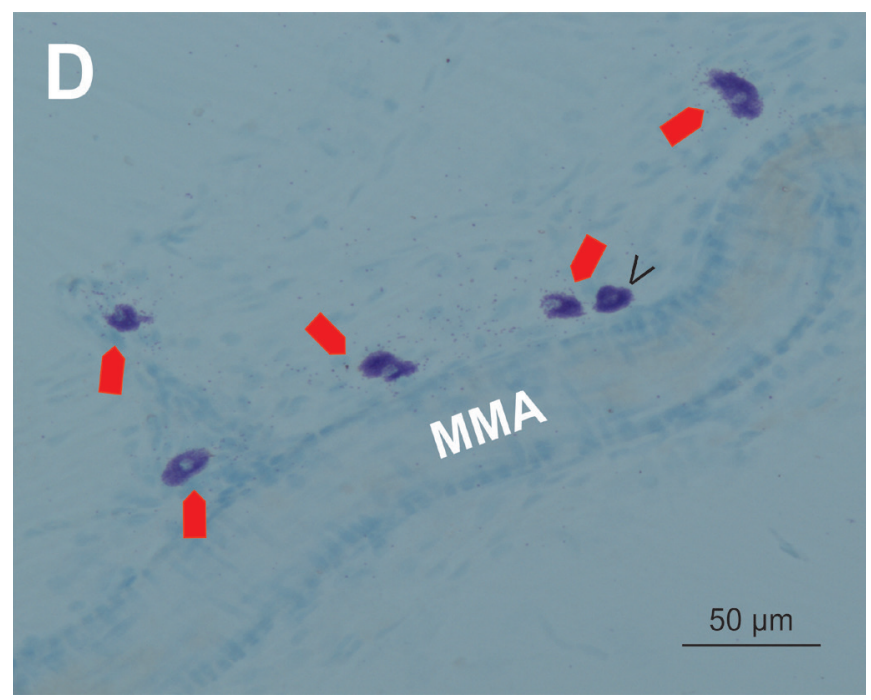

Figure 2D. Mast cell mediator suspension-induced massive degranulation of mast cells in the dura mater in peritoneal mast cell mediator suspension treatment group. X20 magnification. While open arrowheads show intact mast cells, red solid arrowheads show degranulated mast cells (staining, toluidine blue). MMA: middle meningeal artery.

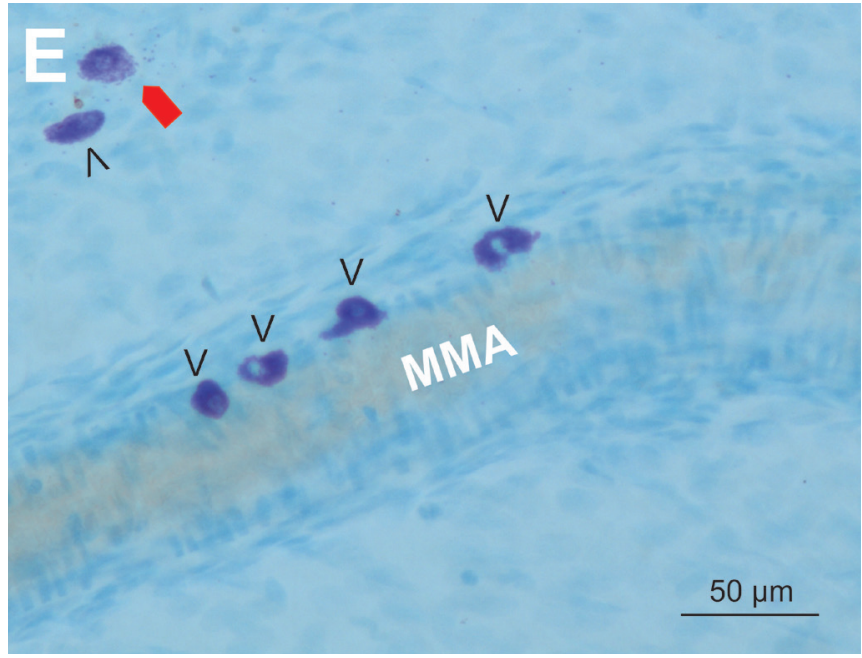

Figure 2E. Inhibition of mast cell degranulation in the dura mater by cromolyn in cromolyn plus mast cell mediator suspension group. X20 magnification. While open arrowheads show intact mast cells, red solid arrowheads show degranulated mast cells (staining, toluidine blue). MMA: middle meningeal artery.

\section{DISCUSSION}

The mast cell degranulator compound $48 / 80$ is a synthetic secretagogue agent and widely used for non-IgE dependent activation of mast cells. Compound 48/80 treatment stimulates inflammatory responses in a variety of animal models such as systemic anaphylaxis (20), central nervous system inflammation (21), dural neurogenic inflammation and activation of trigeminal neurons in migraine (22), mast cell-mediated hyperalgesia (23), allergic inflammation and neuropathic pain (24). But in these models, compound $48 / 80$ treatment leads to systemic mast cell degranulation throughout all body. Such applications make it difficult to focus on a specific disease in animal models of acute and chronic inflammation. The local application of compound $48 / 80$ can solve the problem at the least in the tissues containing mast cells. In relation to this, we have recently shown that topical application of compound 48/80 to meninges evoked potently nociceptive firing in meningeal trigeminal nerve fibers in ex-vivo rat meningeal preparations through mast cell degranulation (22). But it is hard to see a specific or local effect of compound $48 / 80$ treatment during in vivo applications because compound $48 / 80$ diffuses almost all tissues of the body when it is injected. Therefore, in the present study, we used MC mediator suspension obtained from peritoneal mast cells degranulated by compound $48 / 80$ for the first time to develop a model with both local and systemic effect for inflammatory diseases.

MC mediator suspension treatment exhibited more powerful effects than the effect of compound $48 / 80$ on the plasma SP levels and number as well as degranulation of mast cells in the dura mater which are the most important markers of inflammation and acute inflammatory pain. In the present study, we chose plasma SP levels, and number 
and degranulation states of mast cells in the dura mater to evaluate inflammation and inflammatory pain because of these parameters are accepted as valuable markers in most inflammatory diseases $(3,7,12,25,26)$.

It is known that mast cells and SP contribute a plethora of proinflammatory effects $(12,25)$. It was reported that SP levels and NK-1R expression were increased in the rectum and colon of patients with inflammatory bowel disease and in the synovial fluid and serum of patients with rheumatoid arthritis $(27,28)$. Moreover, SP leads to release of inflammatory mediators such as cytokines, serotonin, histamine, TNF- $\alpha$, oxygen radicals and arachidonic acid derivatives from mast cells through receptor-independent mechanism. In a clinical study, a positive correlation has been shown between the plasma levels of SP and intensity of chronic pain in patients with osteoarthritis and rheumatoid arthritis (12). In the present study, we showed that intraperitoneal administration of compound $48 / 80$ raised the plasma levels of SP, which is a critical marker of inflammation and inflammatory pain. However, mast cell stabilizers are also very important agents to control the plasma levels of SP in certain inflammatory diseases. It was reported that pretreatment with the mast cell stabilizer cromolyn decreased plasma levels of SP, CGRP and tryptase in transgenic sickle mice (29). Likewise, in the current study, pretreatment with the mast cell stabilizer cromolyn significantly diminished plasma levels of SP induced by compound $48 / 80$ or mast cell mediator suspension. Inhibition of mast cell activation can be a considerable tool to prevent subsequent chronic inflammatory conditions such as asthma, headache, allergic and rheumatic disorders. For example, some mast cell stabilizers including ketotifen and cromolyn have been successfully used in the treatment of various allergic disorders (9). Moreover, reduction of mast cell numbers and/or inhibition of mast cell degranulation in their resident environment are also very important in the treatment of inflammatory diseases.

In the current study, cromolyn inhibited mast cell degranulation in the dura mater evoked by compound $48 / 80$ or mast cell mediator suspension. Moreover, cromolyn decreased also mast cell mediator suspension-induced increments in the number of mast cells in the dura mater. Our findings are in accordance with the literature reporting the effects of the number and degranulation of mast cells in the inflammatory diseases $(6,7,26)$. Previously published studies in the literature reported that there is an increase in the number and degranulation of mast cells in inflammatory pain conditions $(6,7,26)$. The cranial dura mater is densely innervated by trigeminal afferent nerve fibers, and contains numerous mast cells.

Chemical or mechanical irritation of the dura mater causes release of vasoactive and proinflammatory neuropeptides such as SP and CGRP from trigeminal nerve terminals innervating the dura mater $(4,30,31)$. Released SP and CGRP leads to plasma protein extravasation, vasodilatation of meningeal blood vessels and dural mast cell degranulation which constitute triple trivet of dural neurogenic inflammation underlying migraine pain (5). Moreover degranulated mast cells in the dura mater release vasoactive, nociceptive and proinflammatory mediators such as SP, CGRP, serotonin, prostaglandins, histamine and a plethora of cytokines (2) which, in turn, further strengthen dural neurogenic inflammation and pain. On this basis, researchers developed an animal model of migraine through applying an inflammatory cocktail to dura mater to induce local inflammation at the dura mater $(32,33)$. This inflammatory cocktail known as inflammatory soup comprises an combination of serotonin, bradykinin, histamine, and prostaglandin PGE2. Mast cells are known to contain these mediators. Such animal models to study inflammatory pain and hyperalgesia cannot mimic all characteristics of inflammatory pains due to the presence of only mast cell derived limited mediators such as serotonin, bradykinin, histamine, and prostaglandin PGE2. Therefore, in the current study, we suggest a more realistic model including application of $\mathrm{MC}$ derived mediators to study mechanisms, pathophysiology and treatment of local or systemic inflammatory diseases. Moreover this new method has a number of advantages compared to existing methods. These are i) mast cell mediator suspension contain all mediators in the cytoplasmic granules of mast cells, ii) mediators used in the study are not synthetic, iii) the mediator suspension is autologous, iv) the mediator suspension also contains cytokines that are responsible for a broad spectrum of inflammatory responses, v) the mediator suspension can be applied intraperitoneally to induce systemic inflammatory conditions, or topically to constitute site-specific inflammatory diseases, vi) it can also be injected to cutaneous tissues, joints and muscles to establish local inflammatory diseases, vii) mast cell stabilizer cromolyn can be used as positive control to compare efficacy of new therapeutic agents for the treatment of inflammatory diseases.

\section{CONCLUSION}

Our results showed that administration of mast cell mediator suspension exhibited more potent inflammatory effects than compound 48/80 treatment, in terms of the increments in the plasma SP levels and the number and degranulation of dural MCs. Therefore intraperitoneal administration of mast cell mediator suspension could be a useful tool to investigate mechanisms of inflammatory conditions that are particularly associated with the degranulation of MCs.

However, our study has several limitations. These limitations are i) other inflammatory markers including, IL-1 $\beta$, bradykinin, TNF- $\alpha$ in peripheral blood should be studied following autologous mast cell mediator suspension administration, ii) in addition to pain and inflammatory markers in the plasma, behavioral tests such as von Frey and hot plate as indicator for the pain should also be performed to evaluate mast cell mediator suspension-induced inflammatory pain, iii) dose adjustment of autologous mast cell mediator suspension 
administration should be studied in rats, mice and rabbits, and iv) further studies supporting our results are required.

Conflict of Interest: All authors declare no conflict of interest.

Financial Disclosure: No financial support by any institution. Authors financially supported this study.

\section{REFERENCES}

[1] Schlereth T, Birklein F. Mast cells: source of inflammation in complex regional pain syndrome? Anesthesiol. 2012; 116:756-7.

[2] Theoharides TC, Alysandratos KD, Angelidou A, Delivanis DA, Sismanopoulos N, Zhang B, Asadi S, Vasiadi M, Weng Z, Miniati A, Kalogeromitros D. Mast cells and inflammation. Biochim. Biophys. Acta 2012; 1822:21-33.

[3] Sismanopoulos N, Delivanis DA, Alysandratos KD, Angelidou A, Therianou A, Kalogeromitros D, Theoharides TC. Mast cells in allergic and inflammatory diseases. Curr. Pharm. Des. 2012;18:2261-2277.

[4] Kilinc E, Dagistan Y, Kukner A, Yilmaz B, Agus S, Soyler G, Tore F. Salmon calcitonin ameliorates migraine pain through modulation of CGRP release and dural mast cell degranulation in rats. Clin. Exp. Pharmacol. Physiol. 2018; 45(6):536-546.

[5] Kilinc E, Dagistan Y, Tore F. Mast cell degranulation mediates compound 48/80-induced meningeal vasodilatation underlying migraine pain. Clin. Exp. Health Sci. 2017; 196-201.

[6] Aich A, Afrin LB, Gupta K. Mast cell-mediated mechanisms of nociception. Int. J. Mol. Sci. 2015;16:29069-29092.

[7] Héron A, Dubayle D. A focus on mast cells and pain. J. Neuroimmunol. 2013;264:1-7.

[8] Manchanda RK, Jaggi AS, Singh N. Ameliorative potential of sodium cromoglycate and diethyldithiocarbamic acid in restraint stress-induced behavioral alterations in rats. Pharmacol. Rep. 2011;63:54-63.

[9] Finn DF, Walsh JJ. Twenty-first century mast cell stabilizers. Br. J. Pharmacol.2013;170:23-37.

[10] da Silva EZ, Jamur MC, Oliver C. Mast cell function: a new vision of an old cell. J. Histochem. Cytochem. 2014;62:698-738.

[11] Bozic CR, Lu B, Höpken UE, Gerard C, Gerard NP. Neurogenic amplification of immune complex inflammation. Science 1996;273:1722-5.

[12] Lisowska B, Lisowski A, Siewruk K. Substance P and chronic pain in patients with chronic inflammation of connective tissue. PLoS One 2015;10:e0139206.

[13] Straub RH, Cutolo M. Involvement of the hypothalamicpituitary-adrenal/gonadal axis and the peripheral nervous system in rheumatoid arthritis: viewpoint based on a systemic pathogenetic role. Arthritis Rheum. 2001;44:493-507.

[14] Clay F, Morris C. British inflammation research association meeting: is there any point in developing an anti-RA drug? National Heart and Lung Institute, London, UK, 21-22 November 1996. Inflamm. Res. 1997;46:243-245.

[15] Gabrielian L, Helps SC, Thornton E, Turner RJ, Leonard AV, Vink $R$. Substance $P$ antagonists as a novel intervention for brain edema and raised intracranial pressure. Acta Neurochir. Suppl. 2013;118:201-204.

[16] Zhang RX, Ren K. Animal models of inflammatory pain. Ma C., Zhang JM, editors. Animal models of pain. Totowa, NJ: Humana Press; 2011. p.23-41.
[17] Levy D, Burstein R, Kainz V, Jakubowski M, Strassman AM. Mast cell degranulation activates a pain pathway underlying migraine headache. Pain 2007;130:166-176.

[18] Sand E, Themner-Persson A, Ekblad E. Mast cells reduce survival of myenteric neurons in culture. Neuropharmacol. 2009;56:522-530.

[19] Kilinc E, Dagistan Y, Kotan B, Cetinkaya A. Effects of Nigella sativa seeds and certain species of fungi extracts on number and activation of dural mast cells in rats. Physiol. Int. 2017;104:15-24.

[20] Chakraborty S, Kar N, Kumari L, De A, Bera T. Inhibitory effect of a new orally active cedrol-loaded nanostructured lipid carrier on compound 48/80-induced mast cell degranulation and anaphylactic shock in mice. Int. J. Nanomedicine 2017;12:4849-4868.

[21] Dong H, Zhang X, Wang Y, Zhou X, Qian Y, Zhang S. Suppression of Brain Mast Cells Degranulation Inhibits Microglial Activation and Central Nervous System Inflammation. Mol. Neurobiol. 2017; 54:997-1007.

[22] Kilinc E, Guerrero-Toro C, Zakharov A, Vitale C, Gubert-Olive M, Koroleva K, Timonina A, Luz LL, Shelukhina I, Giniatullina $\mathrm{R}$, Tore F, Safronov BV, Giniatullin R. Serotonergic mechanisms of trigeminal meningeal nociception: Implications for migraine pain. Neuropharmacol. 2017;116:160-173.

[23] Ferrari LF, Levine JD, Green PG. Mechanisms mediating nitroglycerin-induced delayed-onset hyperalgesia in the rat. Neurosci. 2016;317:121-129.

[24] Kaur G, Singh N, Jaggi AS. Mast cells in neuropathic pain: an increasing spectrum of their involvement in pathophysiology. Rev. Neurosci. 2017;28:759-766.

[25] O'Connor TM, O'Connell J, O'Brien DI, Goode T, Bredin CP, Shanahan $F$. The role of substance $P$ in inflammatory disease. J. Cell Physiol. 2004;201:167-180.

[26] Kilinc E, Firat T, Tore F, Kiyan A, Kukner A, Tunçel N. Vasoactive Intestinal peptide modulates c-Fos activity in the trigeminal nucleus and dura mater mast cells in sympathectomized rats. J. Neurosci. Res. 2015;93:644-650.

[27] Menkes CJ, Renoux M, Laoussadi S, Mauborgne A, Bruxelle J, Cesselin F. Substance P levels in the synovium and synovial fluid from patients with rheumatoid arthritis and osteoarthritis. J. Rheumatol. 1993;20:714-717.

[28] Tavano F, di Mola FF, Latiano A, Palmieri O, Bossa F, Valvano MR, Latiano T, Annese V, Andriulli A, di Sebastiano P. Neuroimmune interactions in patients with inflammatory bowel diseases: disease activity and clinical behavior based on Substance $P$ serum levels. J. Crohns Colitis 2012;6:563-70.

[29] Vincent L, Vang D, Nguyen J, Gupta M, Luk K, Ericson ME, Simone DA, Gupta K. Mast cell activation contributes to sickle cell pathobiology and pain in mice. Blood 2013; 122:1853-62.

[30] Waeber C, Moskowitz MA. Migraine as an inflammatory disorder. Neurology 2005;64:S9-15.

[31] Peroutka SJ. Neurogenic inflammation and migraine: implications for the therapeutics. Mol.Interv. 2005;5:304-11.

[32] Strassman AM, Raymond SA, Burstein R. Sensitization of meningeal sensory neurons and the origin of headaches. Nature 1996; 384:560-4.

[33] Burstein R, Yamamura H, Malick A, Strassman AM. Chemical stimulation of the intracranial dura induces enhanced responses to facial stimulation in brain stem trigeminal neurons. J. Neurophysiol. 1998;79:964-82. 
How to cite this article: Kilinc E., Dagistan Y, Cetinkaya A, Tore F. The Comparison of Effects of Applications of Compound 48/80 and Mast Cell Mediator Suspension on Inflammation in Rats: A Methodological Study for Acute Inflammatory Pain. Clin Exp Health Sci 2019; DOI: 10.5152/clinexphealthsci.2018.923 